\title{
Hybrid Methodologies for Segmentation and Classification of Skin Diseases: A Study
}

\author{
Md. Al Mamun' ${ }^{(1)}$, Mohammad Shorif Uddin² \\ ${ }^{1}$ Department of Public Health and Informatics, Jahangirnagar University, Savar, Dhaka, Bangladesh \\ ${ }^{2}$ Department of Computer Science and Engineering, Jahangirnagar University, Savar, Dhaka, Bangladesh \\ Email: almamun@juniv.edu, shorifuddin@juniv.edu
}

How to cite this paper: Mamun, Md.A. and Uddin, M.S. (2021) Hybrid Methodologies for Segmentation and Classification of Skin Diseases: A Study. Journal of Computer and Communications, 9, 67-84. https://doi.org/10.4236/jcc.2021.94005

Received: March 4, 2021

Accepted: April 16, 2021

Published: April 19, 2021

Copyright () 2021 by author(s) and Scientific Research Publishing Inc. This work is licensed under the Creative Commons Attribution International License (CC BY 4.0).

http://creativecommons.org/licenses/by/4.0/

(c) (i) Open Access

\begin{abstract}
Skin disorders are a serious global health problem for humans. These disorders become dangerous when they grow into the malignant stage. Hence, it is necessary to detect these diseases at their early stage. A mobile-based automated skin disease detection system is vital for detecting skin diseases. This system also offers cure or treatment plans to the affected person through the short message service (SMS) or electronic mail (e-mail). An effective skin disease detection system consists of three processes: segmentation, feature extraction, and classification. Several hybrid methodologies are already developed for the above-mentioned processes for detecting skin diseases at the initial stage. This research gives a standard hybrid framework for detecting skin diseases and highlights some design requirements for achieving high accuracy. Existing state-of-the-art hybrid methods of three processes for detecting skin diseases along with their limitations are also summarized. It also identifies the challenges for developing an effective skin disease detection system and gives future research directions.
\end{abstract}

\section{Keywords}

Segmentation, Feature Extraction, Classification, Machine Learning

\section{Introduction}

Skin is the most sensitive part that is more affected than any other human organ. Sunburn is one of the essential elements that affect the melanocytes cell due to the ultraviolet (UV) rays from the sun [1]. The exposer part of the skin is infected with different diseases by the UV rays, fungal or viral infections, and polluted surroundings [2] [3] [4]. The symptoms of skin lesions are aridity of the skin, infectivity, allergic signs, blaze, cough, rough skin, fever, distress, bruises, 
scratching, pimples, and bump, etc. A digital system is required to detect skin diseases at the earlier stage [5] [6]. An expert dermatologist can suspect skin infections at the initial stage. For detecting particular skin diseases in an early stage an automated machine learning or an artificial neural network (ANN) based detection system is essential [7] [8].

For the segmentation and feature extraction process, an enhanced image of the affected portion of skin is used, and extracted features are used in the machine learning or artificial neural network algorithm to identify whether there exist skin diseases or not. The testing and learning units are the two phases of this automated system. In the testing unit, an affected portion of the lesion from a resized filtered skin lesion image is segmented by using a hybrid segmentation algorithm. Then, the system goes to the hybrid feature extraction methods [9]. These methods are very useful in extracting features from the segmented portion of the dermoscopic images. Machine learning or ANN algorithms are used to identify skin diseases by extracting features [10] [11]. These hybrid algorithms based on machine learning or ANN are cost-effective in terms of time and space for classifying skin diseases. In the learning unit, the previously classified skin lesion diseases are stored in the database. Finally, the testing and learning units identify the various skin diseases. If there exist no matches between the test and stored database images, the system will be rechecked [12]. If we can add a treatment plan, it would be very helpful for the patients [13]. Figure 1 illustrates the flow diagram of an automated skin disease detection system.

In this paper, we have analyzed hybrid methodologies of three processes for detecting skin diseases. Among the methodologies, we have found efficient hybrid methods of segmentation, feature extraction, and classification of skin diseases. These automated hybrid methods are functioning effectively with low computational complexity.

The main contributions of this research are as follows:

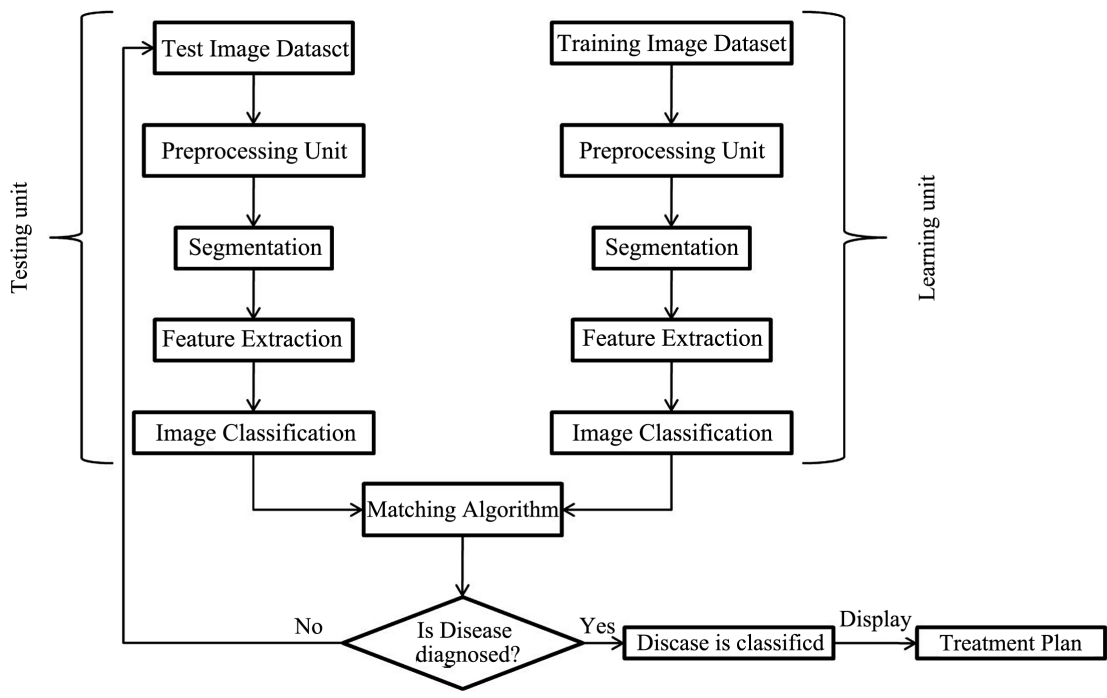

Figure 1. A general framework of the skin disease detection system [12]. 
- We present the current trends of hybrid methodologies for segmentation, feature extraction, and classification.

- We identify the efficient method for diagnosing skin diseases.

- We highlight the limitations and challenges of existing state-of-the-art hybrid methods along with future research directions.

The paper is organized as follows: part II describes the related literature. The general hybrid framework for skin disease detection system is explained by part III. Part IV illustrates the basic design requirements for this hybrid method. The existing state-of-the-art hybrid methods of three processes, such as segmentation, feature extraction, and classification for detecting skin diseases are summarized in part V. Part VI highlights the challenges of hybrid methodologies. Finally, the last section concludes the study along with future research guidelines.

\section{Related Literature}

Several studies [14]-[38] have already been performed for detecting skin diseases. Mahmoud Elgamal [14] proposed an automated system that uses discrete wavelet transform (DWT) for extracting the features of a color-based segmented image portion of the skin lesion. Here, the principal component analysis (PCA) algorithm is used to reduce the features. The proposed system is cost-effective in terms of time and space. Based on the features, the $\mathrm{kNN}$ (k-nearest neighbor) algorithm is used to classify the skin diseases like normal or abnormal with a system accuracy of $97.5 \%$, sensitivity of $100 \%$, and specificity of $95 \%$. But DWT method sometimes could not extract features properly. Another method [15] describes a real-time embedded system that uses the gray-level co-occurrence matrix (GLCM) features are used to classify the skin diseases like melanoma, basal cell carcinoma, actinic keratosis, squamous cell carcinoma through a backpropagation neural network (BPNN). K-means clustering and the Otsu thresholding segmentation method are used for segmentation. Here, the images are clustered with a threshold value. The system provides $95.83 \%$ accuracy. This methodology works only 50 images for four different skin cancer detections and the mechanism of the classification algorithm is not clear. To enhance the system performance of the GLCM color feature-based method, Sumithra et al. [16] proposed a system that uses a region growing method for segmenting the regions of the image. They used various color spaces to extract features like mean, standard deviation, variation, and skewness, angular second moment, contrast, correlation, a sum of variance, inverse difference moment, sum average, sum variance, sum entropy, entropy, difference variance, difference entropy, information measures of correlation, and maximal correlation coefficient, etc. These features are used in the SVM-KNN hybrid method to classify skin diseases as melanoma, bullae, seborrheic keratosis, shingles, and squamous cells with a system accuracy of $98 \%$. But the system will be vulnerable to complex feature sets and sometimes shows mismatch due to dataset.

To minimize dataset problem a preprocessing system [17] namely contrast li- 
mited adaptive histogram equalization technique (CLAHE) with median filtering is used. Here, a segmentation algorithm like normalized Otsu thresholding is used to segment the affected skin lesion portion from the skin. GLCM with geometric features is used as a feature extraction method. PCA algorithm is used to reduce the features to speed up the classification process. DLNN (deep learning neural network) and hybrid-AdaBoost algorithms are used to classify skin diseases. The system gives an accuracy of about $93 \%$.

Another paper [18] describes a system that uses the feature extraction algorithm GLCM with LBP for extracting the features like energy, entropy, contrast, homogeneity, and LBP array. These features are used to classify skin diseases with a system accuracy of $90.32 \%$ and a sensitivity rate of $85.84 \%$. But system accuracy is not somehow low and the system is not embedded in smartphone-based technology. Taufiq et al. [19] explained a smart-phone based system that uses the Grabcut algorithm for segmenting the image in real-time. The histogram-based $\mathrm{ABCD}$ rule is used for extracting the features like lesion perimeter, eccentricity, mean, standard deviation, L1 norm, L2 norm, angle of the lesion, a major-minor axis of the lesion from the segmented image. Skin diseases are classified by SVM with the sensitivity rate and specificity rate of $80 \%$ and $75 \%$, respectively. This method is relatively poor than the previous GLCM-LBP feature extraction method. Method [20] uses a rough-set based feature selection algorithm to extract the features like erythema, scaling, borders, itching, koebner phenomenon, polygonal and follicular papules, oral mucosal involvement, knee-elbow, and scalp involvement, family history, age, etc. These features are used to classify the skin diseases like psoriasis, seborrheic dermatitis, lichen planus, pityriasis rosea, chronic dermatitis, and pityriasis rubra pilaris through SVM-kNN with multilayer perceptron. The obtained system accuracy is about $97 \%$. To minimize extracted features Joseph et al. [21] described a system that works with highly efficient preprocessed $\mathrm{PH}_{2}$ dataset images. The Otsu thresholding method with edge-based morphological operations is used for image segmentation. Here, the edge-based method with pixel values works efficiently with dilation and erosion operations. The method produces a better-segmented image portion. Tan et al. [22] proposed an intelligent decision support system that uses the adaptive snake method which works with the gradient threshold value of grayscale images for segmentation. Here, $A B C D$ rule and Epiluminescence microscopy (ELM) criteria and genetic algorithm (GA) with radial basis function (RBF) based support vector machine (SVM) are used for feature extraction and classification. As the efficiency of this method is somehow low, hence, to enhance the efficiency it requires hybrid segmentation and classification algorithm.

Liao et al. [23] suggested a method that classifies skin diseases based on the characteristics of affected images by using a multi-level convolution neural network (CNN) with block variation of local correlation coefficients (BVLC) based AlexNet model. It provides a poor system accuracy of $70 \%$. This method does 
not use specific segmentation and feature extraction algorithms. In this backdrop, Alquran et al. [24] proposed a method that uses the Otsu thresholding method for segmentation and GLCM-ABCD (area, border, color, and diameter) rule for feature extraction. PCA algorithm is used to find out the optimum features like total dermoscopy score (TDS), mean, standard deviation, energy, contrast, etc. Here, skin diseases are classified through the SVM from the correlation matrix with a system accuracy of $92.10 \%$. If the system uses a hybrid classification algorithm like SVM with kNN or SVM with a decision tree (DT) or SVM with CNN, the system accuracy will be enhanced.

Janney et al. proposed a method [25] that describes a system that uses a region-based segmented image portion for extracting features by using the GLCM-based ABCD rule. The extracted features based on $A B C D$ rule are asymmetry, border, color, diameter, total dermoscopy score, and GLCM-based extracting features are energy, entropy, contrast, correlation, etc. Here, the homogeneity is used to classify the skin diseases as benign or malignant by using BPNN with a system accuracy of $90.45 \%$.

In [26] local binary pattern (LBP) method is used for extracting the textural and $\mathrm{ABCD}$ features through the GLCM-based ABCD rule. Through backpropagation neural network (BPNN), the skin is classified as benign or malignant with a system accuracy of $75 \%$ which is also not high enough.

Victor et al. represent a technique [27] that takes preprocessed medical images as input. They used an active contour-based marker control watershed algorithm for image segmentation and statistical GLCM features to classify skin diseases through the SVM algorithm. They obtained an accuracy of $94 \%$. If researchers can use a hybrid classification algorithm, then the system will be more efficient. Ajith et al. [28] described a mobile-based method that uses DCT, DWT, and singular value decomposition (SVD) based feature extraction algorithm. This method can be used in rural area-based mobile health care systems due to its simplicity, but its performance is not up to the mark. Efficient hybrid segmentation or classification algorithm is required to boost up the system performance. To make an efficient system a cloud computing-based skin disease detection system is proposed in [29] that uses the Canny edge detection (CED) algorithm to detect the sharp edges with image boundaries. These boundaries are used to classify different eczema-like: allergic contact eczema, contact eczema, dyshidrotic eczema, neurodermatitis, nummular eczema, seborrhoeic eczema, and stasis dermatitis through the genetic algorithm with BPNN.

Nasir et al. [30] proposed a technique that uses uniform distribution-based segmentation fused with the active contour method. Bajaj et al. [31] also discussed a system that uses edge-based segmentation with an active contour method. In another research [32], a bottom-hat filter is used that speeds up the segmentation process. Otsu thresholding method and morphological operations (dilation-erosion) segment the selected portion from the skin. The Otsu thresholding method concerns with pixels. Here, the skin diseases are classified as 
benign, suspicious, and malignant melanoma by using the $A B C D$ rule, but system accuracy is not mentioned.

In paper [33], a system is proposed that uses GoogleNet-AlexNet, and VGGNet to classify the skin diseases like nevus, melanoma, and seborrheic keratosis. Here, the system accuracy and recall rates are $83.8 \%$ and $84.8 \%$, respectively which is not well enough like DWT-PCA based method.

Paper [34] describes an automated system that uses the Otsu thresholding method for selecting the region of interest (ROI) of the skin lesion portion. The method uses various color models, GLCM, and neighborhood gray-tone difference matrix (NGTDM) for extracting features. The SVM (quadratic kernel) is used to classify skin diseases as acne, eczema, psoriasis, benign, and malignant melanoma, etc. The accuracy (around 83\%) is not so good.

Arasi et al. [35] proposed a system that uses DWT for extracting features for ensuring high accuracy. Here, the wavelet divides an image into four sub-bands like approximation, horizontal, vertical, and diagonal. PCA is used with DWT for reducing the features. Here, the Naive Bayes classifier is used to classify the skin diseases with a system accuracy of $98.8 \%$.

Hameed et al. [36] explained a system that uses Alexnet-pertained CNN to extract the multi-level CNN features of affected portions and to classify the skin diseases like acne, eczema, benign, and malignant through ECOC SVM. The obtained accuracy is low. In [37], the hybrid genetic algorithm with ant colony optimization (ACO-GA) algorithm is used for segmentation with $94 \%$ accuracy. The GLCM and transductive SVM (TSVM) algorithms are used for feature extraction and classification. The overall system accuracy from the fitness function is $95 \%$. If any method is fused with GLCM then the system would more efficient. In another paper [38], the K-means clustering algorithm is used for segmenting the lesion images and LBP-based GLCM is used for extracting features. SVM is used for classification.

\section{Hybrid Method Framework for Skin Disease Detection}

In an automated skin disease detection system, dermoscopy or clinical images are preprocessed and learned through the image segmentation, feature extraction, classification steps, and then they are stored in the learning database [14] [15] [16] [17]. Hybrid segmentation, feature extraction, and classification algorithm are used for detecting skin diseases efficiently. The matching algorithm unit tests the features that are used to classify skin diseases. Extracting features from testing images is associated with the features of previously-stored learned images [18]. The matching algorithm works in such a way that if diseases are detected, they will be classified, and finally, the patients will get an e-prescription, otherwise, the system identifies it as healthy skin [21] [22] [23] [24]. The patients get associated information like e-prescription through the treatment plan. The above framework for the skin disease detection system is depicted in the following Figure 2. 


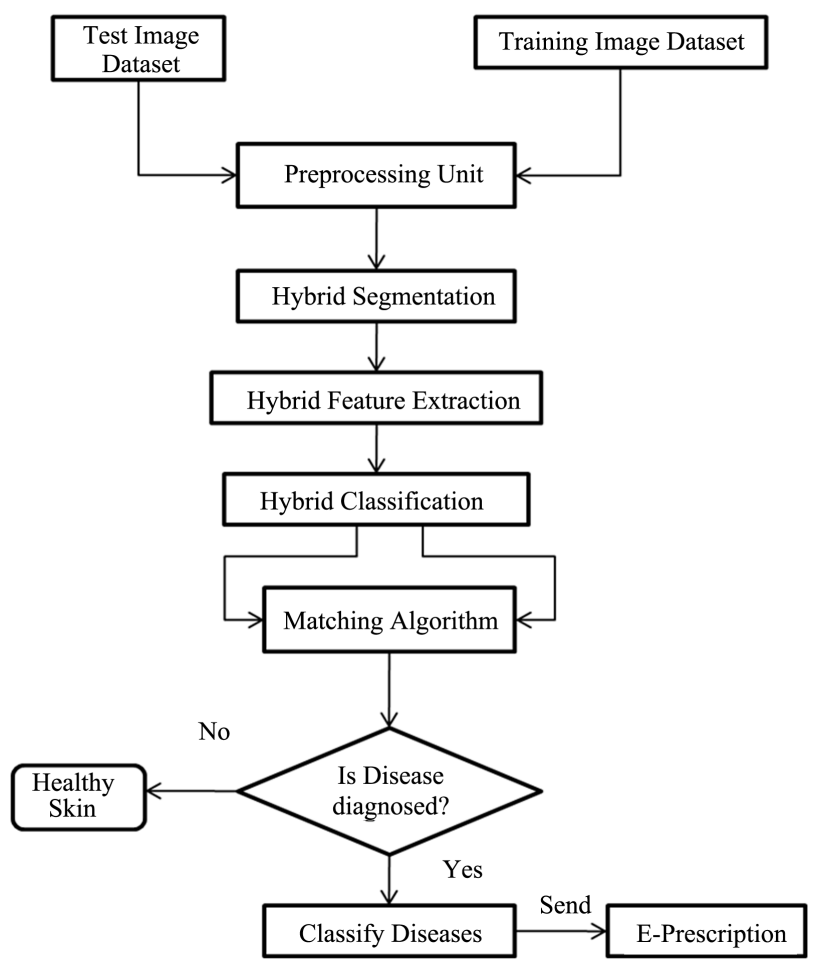

Figure 2. A general framework for a hybrid skin disease detection system.

\section{Design Requirements for Hybrid Skin Disease Detection System}

An automated skin disease detection system predicts the skin diseases within a short period with high throughput. If skin diseases are detected earlier, then life is saved from chronic skin diseases like skin cancer. This section discusses the design requirements of a hybrid skin disease detection system. In real situations, input images are not homogeneous in size, shape, dimension, color, and brightness, etc. Also, effective image segmentation is necessary for predicting skin diseases. If image portions are cropped for feature extractions, the disease classification accuracy may be lower. Some requirements must be satisfied for designing an efficient hybrid digital skin disease detection system. Among other requirements, the four basic requirements are robustness, data partitioning, data extraction, and predictability. These basic requirements are depicted in Figure 3.

Robustness is the requirement where the affected skin image can still be detected after this image has been affected by some common image processing operations include resizing, scaling, translation, spatial filtering, rotation, color mapping, noise, and lossy compression.

Data partitioning is another requirement of a hybrid skin disease detection method that segments the affected image portion for skin disease prediction [3] [4]. The segmentation technique partitions images into few (under-segmentation) or too many regions (over-segmentation). Data extraction is to extract the features that are generated from the segmented image portion. These extracted features are used to classify skin diseases efficiently [5] [6]. Predictability is also an 


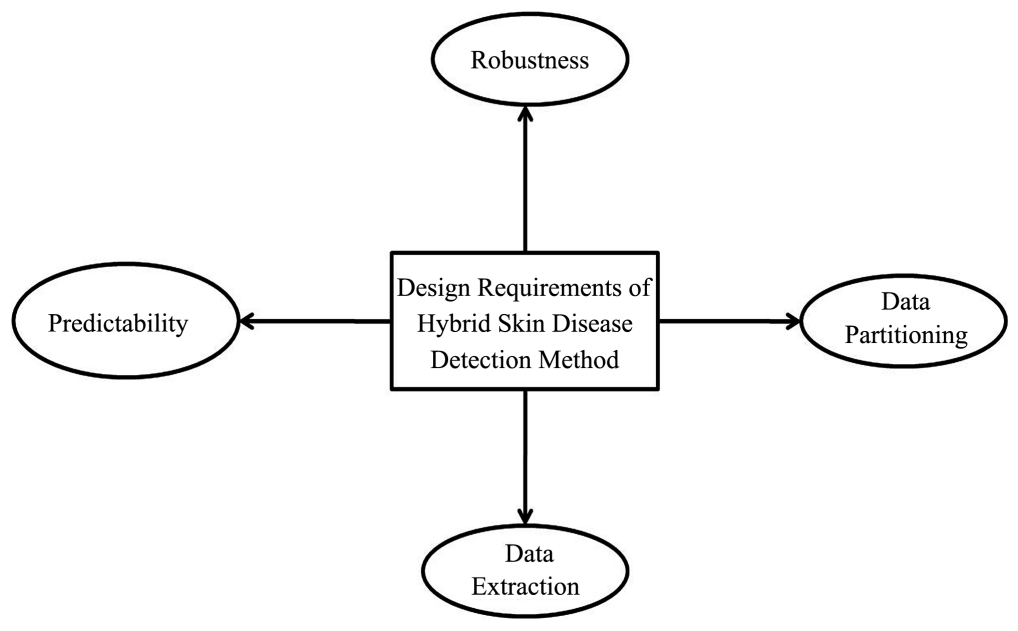

Figure 3. Basic requirements of hybrid skin disease detection method.

important criterion for an automated skin disease detection system. Machine learning and artificial intelligence algorithms are used to predict skin diseases [7]-[12]. The predicted skin diseases are classified as healthy, benign, suspicious, and malignant.

\section{Summary of the State-of-the-Art Hybid Methods}

A hybrid method means the two algorithms work simultaneously in a skin disease detection system. Usually, the performance and efficiency of the skin disease detection system are estimated by using the confusion matrix. The parameters for evaluating the performance are accuracy, sensitivity, specificity, precision, recall, and F-measure, which are calculated by using the values of true positive (TP), true negative (TN), false positive (FP), and false-negative (FN) values of selected lesion images [14] [16] [17] [19] [31] [33]. This section describes the hybrid methodologies of segmentation, feature extraction, and classification for detecting skin diseases.

\section{1) Hybrid Methodologies of Image Segmentation}

There are various hybrid methods for image segmentation. Figure 4 shows the picture of important hybrid-based methods.

The current state-of-the-art hybrid methodologies of image segmentation are explained in Table 1 . This table contains used datasets, preprocessing, segmentation and its characteristics, feature extraction, classification method, advantages or disadvantages of hybrid techniques, and accuracy of skin disease detection system.

Based on Table 1, we can say that uniform distribution-based segmentation fused with the active contour method is robust among hybrid segmentation methods as it gives the highest system accuracy of $97.5 \%$.

\section{2) Hybrid Methodologies of Feature Extraction}

There are various hybrid methods for feature extraction from the captured skin images. Figure 5 shows the picture of important hybrid-based feature extraction methods. 
Table 1. Hybrid methodologies of image segmentation.

\begin{tabular}{|c|c|c|c|c|c|c|c|}
\hline $\begin{array}{l}\text { Techniques } \\
\text { (Reference } \\
\text { number is } \\
\text { mentioned) }\end{array}$ & Segmentation & Characteristics & $\begin{array}{l}\text { Feature } \\
\text { extraction }\end{array}$ & Classification & Advantages & Limitations & Accuracy \\
\hline [15] & $\begin{array}{c}\text { K-means } \\
\text { clustering + Otsu } \\
\text { method }\end{array}$ & $\begin{array}{c}\text { Images are clustered } \\
\text { with the threshold } \\
\text { value. }\end{array}$ & GLCM & BPNN & $\begin{array}{l}\text { An NN-based system } \\
\text { that is in a real-time } \\
\text { embedded manner. }\end{array}$ & $\begin{array}{l}\text { Computational } \\
\text { complexity is high } \\
\text { due to it works in real } \\
\text { time environment. }\end{array}$ & $95.83 \%$ \\
\hline [21] & $\begin{array}{l}\text { Otsu Thresholding } \\
\text { method + Edge-based } \\
\text { Morphological } \\
\text { operations }\end{array}$ & $\begin{array}{l}\text { Edge-based } \\
\text { segmentation with } \\
\text { threshold values. }\end{array}$ & $\begin{array}{c}\text { 2-D Fast } \\
\text { Fourier } \\
\text { Transform, } \\
\text { 2-D Discrete } \\
\text { Cosine } \\
\text { Transform, } \\
\text { Complexity } \\
\text { Feature Set, } \\
\text { and Color } \\
\text { Feature Set }\end{array}$ & SVM & $\begin{array}{l}\text { An enriched } \\
\text { filtering } \\
\text { algorithm helps } \\
\text { all other stages } \\
\text { to perform } \\
\text { efficiently. }\end{array}$ & $\begin{array}{l}\text { Well defined feature } \\
\text { extraction algorithm } \\
\text { is required to } \\
\text { enhance accuracy. }\end{array}$ & $93.50 \%$ \\
\hline [27] & $\begin{array}{l}\text { The active contour } \\
\text { method + Marker } \\
\text { control watershed } \\
\text { algorithm. }\end{array}$ & $\begin{array}{l}\text { The output of the } \\
\text { active contour is used } \\
\text { as an input to } \\
\text { the marker control } \\
\text { watershed algorithm }\end{array}$ & GLCM & SVM & $\begin{array}{l}\text { A CAD system } \\
\text { enhances the } \\
\text { detection and } \\
\text { classification and } \\
\text { reduces the time } \\
\text { latency. }\end{array}$ & $\begin{array}{c}\text { An NN-based } \\
\text { classification } \\
\text { approach is needed. }\end{array}$ & $94 \%$ \\
\hline [30] & $\begin{array}{l}\text { Uniform distribution } \\
\text { based } \\
\text { segmentation }+ \text { Active } \\
\text { contour method }\end{array}$ & $\begin{array}{l}\text { Four metrics: DICE, } \\
\text { Jaccard Index, } \\
\text { Jaccard Difference, } \\
\text { and Diameter are } \\
\text { calculated for each } \\
\text { segmented image. }\end{array}$ & $\begin{array}{l}\text { Color } \\
\text { features }\end{array}$ & SVM & $\begin{array}{l}\text { It is a robust skin } \\
\text { disease detection } \\
\text { system with value. }\end{array}$ & $\begin{array}{l}\text { Reliable and low } \\
\text { complexity based } \\
\text { feature extraction } \\
\text { method is required. }\end{array}$ & $97.5 \%$ \\
\hline [31] & $\begin{array}{c}\text { Edge-based } \\
\text { segmentation + ACM }\end{array}$ & $\begin{array}{l}\text { The active contours } \\
\text { method works with } \\
\text { sharp edges. }\end{array}$ & $\begin{array}{c}\text { Sobel } \\
\text { Operator }\end{array}$ & BPNN & $\begin{array}{c}\text { An NN-based } \\
\text { method that } \\
\text { successfully detects } \\
\text { several diseases. }\end{array}$ & $\begin{array}{l}\text { An efficient hybrid } \\
\text { feature extraction } \\
\text { algorithm is needed. }\end{array}$ & $90 \%$ \\
\hline [32] & $\begin{array}{l}\text { Otsu thresholding } \\
\text { method }+ \\
\text { Morphological } \\
\text { operations: } \\
\text { dilation, erosion }\end{array}$ & $\begin{array}{l}\text { A morphological } \\
\text { operation performs } \\
\text { on pixels. }\end{array}$ & $\mathrm{ABCD}$ rule & - & $\begin{array}{l}\text { Almost all of the } \\
\text { melanoma images } \\
\text { are correctly } \\
\text { identified using } \\
\text { morphological } \\
\text { operations. }\end{array}$ & $\begin{array}{l}\text { Without a trained } \\
\text { neural network, } \\
\text { diseases are not } \\
\text { classified properly. }\end{array}$ & - \\
\hline [37] & $\begin{array}{l}\mathrm{ACO}+\mathrm{GA} \\
\text { algorithm }\end{array}$ & $\begin{array}{l}\text { Initialize GA and } \\
\text { ACO parameters. } \\
\text { Segmentation } \\
\text { accuracy is } 94 \% \text {. }\end{array}$ & GLCM & $\begin{array}{l}\text { Transductive } \\
\text { Support } \\
\text { Vector } \\
\text { Machine } \\
\text { (TSVM) }\end{array}$ & $\begin{array}{l}\text { Better segmentation } \\
\text { accuracy gives high } \\
\text { performance. } \\
\text { At first, this system } \\
\text { is predicted as } \\
24 \text { diseases with } \\
\text { fitness function. }\end{array}$ & $\begin{array}{l}\text { Hybrid feature } \\
\text { extraction } \\
\text { is required. }\end{array}$ & $95 \%$ \\
\hline
\end{tabular}

The hybrid methodologies for feature extraction are described in the following Table 2. This table contains used datasets, segmentation method, feature extraction method and its features, classification method, advantages or disadvantages of methods, and accuracy of skin disease detection system. 
Md. A. Mamun, M. S. Uddin

Table 2. Hybrid methodologies for feature extraction.

\begin{tabular}{|c|c|c|c|c|c|c|c|}
\hline $\begin{array}{l}\text { Techniques } \\
\text { (Reference } \\
\text { number is } \\
\text { mentioned) }\end{array}$ & Segmentation & $\begin{array}{l}\text { Feature } \\
\text { extraction }\end{array}$ & Features & Classification & Advantages & Limitations & Accuracy \\
\hline [14] & $\begin{array}{c}\text { Color } \\
\text { segmentations }\end{array}$ & DWT + PCA & $\begin{array}{l}\text { Features are extracted } \\
\text { from DWT which } \\
\text { are reduced for } \\
\text { better accuracy. }\end{array}$ & $\mathrm{kNN}$ & $\begin{array}{l}\text { It requires less } \\
\text { computational } \\
\text { time and } \\
\text { memory. }\end{array}$ & $\begin{array}{l}\text { DWT requires huge } \\
\text { capacity and is } \\
\text { computationally } \\
\text { more expensive. }\end{array}$ & $97.5 \%$ \\
\hline [17] & $\begin{array}{l}\text { Normalized } \\
\text { Otsu } \\
\text { thresholding }\end{array}$ & GLCM+ PCA & $\begin{array}{c}\text { Mean, standard } \\
\text { deviation, variance, } \\
\text { entropy, } \\
\text { contrast/inertia, } \\
\text { homogeneity, energy, } \\
\text { correlation, area, } \\
\text { perimeter, diameter, } \\
\text { asymmetry index, } \\
\text { circularity index, } \\
\text { fractal dimension, } \\
\text { compactness index }\end{array}$ & $\begin{array}{c}\text { DLNN } \\
\text { (Deep } \\
\text { learning NN), } \\
\text { SVM-Adaboost }\end{array}$ & $\begin{array}{l}\text { This is a CAD } \\
\text { system that } \\
\text { runs with lower } \\
\text { computational } \\
\text { time with } \\
\text { higher } \\
\text { accuracy. }\end{array}$ & $\begin{array}{l}\text { Hybrid } \\
\text { segmentation is } \\
\text { needed to } \\
\text { enhance system } \\
\text { performance. }\end{array}$ & $93 \%$ \\
\hline [18] & - & GLCM + LBP & $\begin{array}{l}\text { Energy, entropy, } \\
\text { contrast, homogeneity, } \\
\text { and LBP array } \\
\text { features. }\end{array}$ & SVM & $\begin{array}{c}\text { System } \\
\text { performances } \\
\text { are computed } \\
\text { both } \\
\text { qualitatively } \\
\text { and } \\
\text { quantitatively. }\end{array}$ & $\begin{array}{l}\text { The segmentation } \\
\text { algorithm is } \\
\text { undefined and to } \\
\text { boost up system } \\
\text { performance NN } \\
\text { based classification } \\
\text { is required. }\end{array}$ & 90.32 \\
\hline [19] & $\begin{array}{l}\text { Grab Cut } \\
\text { algorithm }\end{array}$ & $\begin{array}{c}\text { Histogram }+\mathrm{ABCD} \\
\text { rule }\end{array}$ & $\begin{array}{l}\text { Features are the } \\
\text { area of the lesion, } \\
\text { perimeter of a lesion, } \\
\text { eccentricity, mean, } \\
\text { standard deviation, } \\
\text { L1 norm, L2 norm } \\
\text { angle of lesion, major } \\
\text { and minor axis of the } \\
\text { lesion from the } \\
\text { segmented image. }\end{array}$ & SVM & $\begin{array}{l}\text { It is easy to } \\
\text { access and use } \\
\text { due to its } \\
\text { Smartphone } \\
\text { embedded } \\
\text { applications. }\end{array}$ & $\begin{array}{l}\text { An improper } \\
\text { segmentation } \\
\text { algorithm is used } \\
\text { which degrades } \\
\text { system performance. }\end{array}$ & . \\
\hline [22] & $\begin{array}{l}\text { Threshold-based } \\
\text { Adaptive Snake } \\
\text { (AS) approach }\end{array}$ & $\begin{array}{c}\text { ABCD rule + } \\
\text { Epiluminescence } \\
\text { microscopy (ELM) } \\
\text { criteria algorithm }\end{array}$ & $\begin{array}{l}\text { Features extracted in } \\
\text { ABCD rule with ELM } \\
\text { criteria. }\end{array}$ & $\begin{array}{c}\text { GA + SVM with } \\
\text { Radial Basis } \\
\text { Function } \\
\text { (RBF) }\end{array}$ & $\begin{array}{l}\text { GA reduces } \\
\text { the dimensions } \\
\text { and also defines } \\
\text { the most } \\
\text { discriminating } \\
\text { subsets of } \\
\text { features to } \\
\text { boost system } \\
\text { performance. }\end{array}$ & $\begin{array}{l}\text { An efficient and } \\
\text { reliable } \\
\text { segmentation } \\
\text { algorithm is } \\
\text { required. }\end{array}$ & $88 \%$ \\
\hline [24] & $\begin{array}{l}\text { Otsu } \\
\text { thresholding }\end{array}$ & $\begin{array}{c}\text { GLCM + ABCD } \\
\text { rule + PCA }\end{array}$ & $\begin{array}{l}\text { GLCM features are } \\
\text { Energy, correlation, } \\
\text { homogeneity, and } \\
\text { contrast features. The } \\
\text { best } 5 \text { features with } \\
\text { maximum efficiency } \\
\text { as follows: TDS, mean, } \\
\text { standard deviation, } \\
\text { energy, and contrast } \\
\text { respectively. }\end{array}$ & SVM & $\begin{array}{l}\text { The } \\
\text { computational } \\
\text { complexity is } \\
\text { relatively lower } \\
\text { than others. }\end{array}$ & $\begin{array}{c}\text { Hybrid } \\
\text { segmentation } \\
\text { and NN-based } \\
\text { classification } \\
\text { are needed. }\end{array}$ & $92.10 \%$ \\
\hline
\end{tabular}




\section{Continued}

\begin{tabular}{|c|c|c|c|c|c|c|c|}
\hline [25] & $\begin{array}{l}\text { Region-based } \\
\text { Segmentation }\end{array}$ & $\mathrm{ABCD}$ rule $+\mathrm{GLCM}$ & $\begin{array}{l}\text { Asymmetry, border, } \\
\text { color, and differential } \\
\text { structure. TDS }= \\
{[(\mathrm{A} \times 1.3)+(\mathrm{B} \times 0.1)+} \\
(\mathrm{C} \times 0.5)+(\mathrm{D} \times 0.5)] \\
\text { Energy, Entropy, } \\
\text { Contrast, Correlation, } \\
\text { and Homogeneity. }\end{array}$ & BPNN & $\begin{array}{l}\text { Due to NN } \\
\text { based system, } \\
\text { speed up the } \\
\text { system } \\
\text { performance. }\end{array}$ & $\begin{array}{c}\text { A hybrid } \\
\text { classification } \\
\text { algorithm is needed. }\end{array}$ & 90.45 \\
\hline [26] & - & GLCM + ABCD rule & $\begin{array}{l}\mathrm{ABCD} \text { and textural } \\
\text { features are extracted. }\end{array}$ & BPNN & $\begin{array}{l}\text { Due to the } \\
\text { based system, } \\
\text { it is secure } \\
\text { and reliable. }\end{array}$ & $\begin{array}{c}\text { The segmentation } \\
\text { method is not } \\
\text { properly } \\
\text { maintained. }\end{array}$ & $75.00 \%$ \\
\hline [28] & - & $\begin{array}{c}\text { DCT + DWT + SVD } \\
\text { (Singular value } \\
\text { decomposition) }\end{array}$ & $\begin{array}{l}\text { Different coefficients } \\
\text { are extracted which } \\
\text { classify through SVD. }\end{array}$ & - & $\begin{array}{l}\text { Due to } \\
\text { mobile-based } \\
\text { apps, it is used } \\
\text { in mobile } \\
\text { hospitals in } \\
\text { rural remote } \\
\text { areas with a } \\
\text { lower } \\
\text { computational } \\
\text { time of } 2.066 \mathrm{~s} \text {. }\end{array}$ & $\begin{array}{c}\text { Lack of } \\
\text { segmentation and } \\
\text { classification } \\
\text { method, system } \\
\text { performance is } \\
\text { relatively poor. }\end{array}$ & $80 \%$ \\
\hline [33] & - & $\begin{array}{c}\text { GoogleNet + } \\
\text { AlexNet + VGGNet }\end{array}$ & $\begin{array}{c}\text { The convolution } \\
\text { layer-based approach } \\
\text { generates features for } \\
\text { classification. }\end{array}$ & - & $\begin{array}{l}\text { Skin diseases } \\
\text { are classified } \\
\text { as Nevus, } \\
\text { melanoma, } \\
\text { Seborrheic } \\
\text { Keratosis } \\
\text { with lower } \\
\text { computational } \\
\text { time efficiency } \\
\text { with the recall } \\
\text { rate is } 84.8 \% \text {. }\end{array}$ & $\begin{array}{l}\text { Segmentation and } \\
\text { classification } \\
\text { algorithm is not } \\
\text { defined. }\end{array}$ & 83.8 \\
\hline [34] & $\begin{array}{l}\text { Otsu } \\
\text { thresholding }\end{array}$ & GLCM + NGTDM & $\begin{array}{l}23 \text { color and texture } \\
\text { features are as Rmin, } \\
\text { Gmin, Bmin, Rmax, } \\
\text { Gmax, Bmax, Rmean, } \\
\text { Gmean, Bmean, } \\
\text { Hmean, Vmean, } \\
\text { Cbmean, Crmean, } \\
\text { Graymean, contrast, } \\
\text { correlation, energy, and } \\
\text { homogeneity whereas } \\
\text { the coarseness, } \\
\text { busyness, complexity, } \\
\text { contrast and } \\
\text { texture length. }\end{array}$ & $\begin{array}{l}\text { SVM with } \\
\text { quadratic } \\
\text { kernel }\end{array}$ & $\begin{array}{l}\text { Though images } \\
\text { are taken from } \\
\text { diverse sources } \\
\text { system } \\
\text { accuracy is } \\
\text { satisfactory. }\end{array}$ & $\begin{array}{l}\text { Few images are } \\
\text { produced the same } \\
\text { features which } \\
\text { deteriorate the } \\
\text { system } \\
\text { performance } \\
\text { adversely. }\end{array}$ & $83 \%$ \\
\hline [35] & - & $\mathrm{DWT}+\mathrm{PCA}$ & $\begin{array}{l}\text { Wavelets divide an } \\
\text { image into } 4 \text { sub-band } \\
\text { components which } \\
\text { correspond to } \\
\text { approximation, } \\
\text { horizontal, vertical, } \\
\text { and diagonal } \\
\text { respectively. }\end{array}$ & $\begin{array}{c}\text { DT, } \\
\text { Naive Bayes }\end{array}$ & $\begin{array}{l}\text { This system is } \\
\text { efficient on a } \\
\text { small dataset } \\
\text { and easy to use. }\end{array}$ & $\begin{array}{l}\text { It is not adequate } \\
\text { in larger datasets. }\end{array}$ & $98.8 \%$ \\
\hline
\end{tabular}




\section{Continued}

\begin{tabular}{|c|c|c|c|c|c|c|c|}
\hline [38] & $\begin{array}{l}\text { K-Means } \\
\text { Clustering }\end{array}$ & GLCM + LBP & $\begin{array}{c}\text { Mean, standard } \\
\text { deviation, variance, } \\
\text { skewness, LBP, and } \\
\text { GLCM features. }\end{array}$ & SVM & $\begin{array}{l}\text { K-means } \\
\text { algorithm } \\
\text { clustering } \\
\text { enhances the } \\
\text { consistency of }\end{array}$ & $\begin{array}{l}\text { Hybrid classification } \\
\text { is not defined. }\end{array}$ & $96 \%$ \\
\hline
\end{tabular}

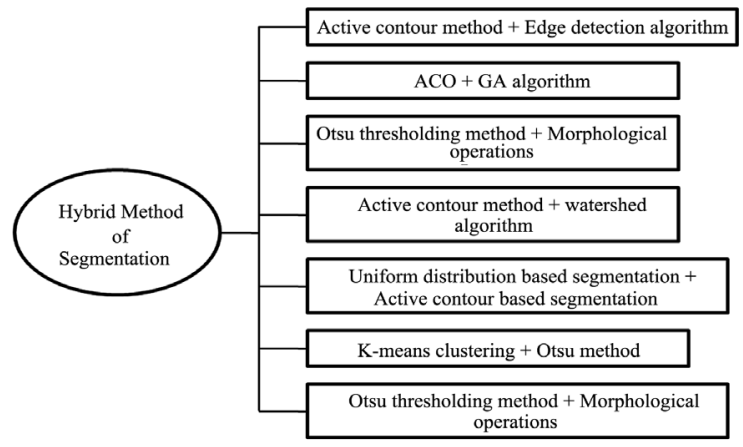

Figure 4. Several hybrid segmentation methods.

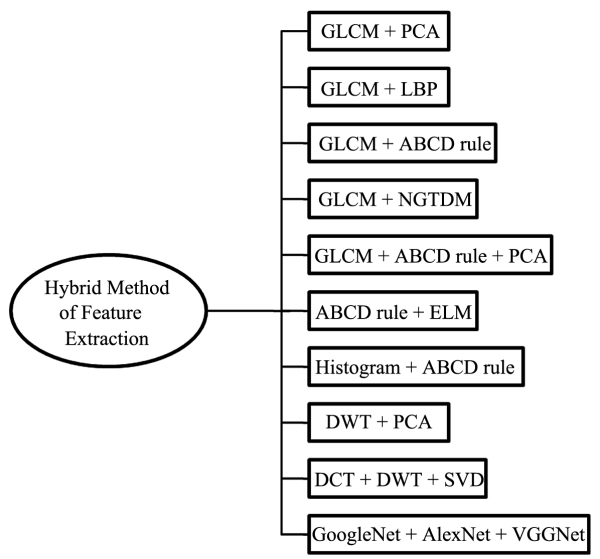

Figure 5. Several hybrid feature extraction methods.

Based on Table 2, we can say that the DWT with PCA method is robust than other hybrid feature extraction methods. DWT wavelets distributed the segmented image into the four sub-band components that extract the features efficiently with the PCA algorithm which reduces the extra features and enhances the classification accuracy. So, we conclude that these methods extract the features very efficiently. The highest classification accuracy of skin disease by using the hybrid feature extraction method is about $98.8 \%$.

\section{3) Hybrid Methodologies for Skin Disease Classification}

There are various hybrid methods for skin-disease classification using the captured skin images. Figure 6 presents the picture of important hybrid-based feature extraction methods.

The existing state-of-the-art hybrid classification methods are explained in the following Table 3. This table describes used datasets, segmentation, feature extraction method, and its features, classification method, advantages or disadvantages, and accuracy of skin disease detection system. 
Table 3. Hybrid methodologies of classification.

\begin{tabular}{|c|c|c|c|c|c|c|c|}
\hline $\begin{array}{l}\text { Techniques } \\
\text { (Reference } \\
\text { number is } \\
\text { mentioned) }\end{array}$ & Segmentation & $\begin{array}{c}\text { Feature } \\
\text { extraction }\end{array}$ & Features & Classification & Advantages & Limitations & Accuracy \\
\hline [16] & $\begin{array}{l}\text { Pixel } \\
\text { based-Region } \\
\text { growing }\end{array}$ & $\begin{array}{l}\text { color and } \\
\text { textural features }\end{array}$ & $\begin{array}{l}\text { Extracted features are } \\
\text { mean, standard deviation, } \\
\text { variation, skewness, } \\
\text { angular second moment, } \\
\text { contrast, correlation, the } \\
\text { sum of variance, inverse } \\
\text { difference moment, sum } \\
\text { average, sum variance, } \\
\text { sum entropy, entropy, } \\
\text { difference variance, } \\
\text { difference entropy, } \\
\text { information measures of } \\
\text { correlation, and maximal } \\
\text { correlation coefficient }\end{array}$ & $\mathrm{SVM}+\mathrm{kNN}$ & $\begin{array}{l}\text { The performance } \\
\text { is high with the } \\
\text { fusion of the } \\
\text { SVM-kNN } \\
\text { classifier. }\end{array}$ & $\begin{array}{l}\text { Dataset is not } \\
\text { standard and the } \\
\text { feature extraction } \\
\text { method is not } \\
\text { defined. }\end{array}$ & $98 \%$ \\
\hline [20] & - & $\begin{array}{l}\text { Rough Set-Based } \\
\text { Feature Selection }\end{array}$ & $\begin{array}{l}\text { Features are erythema, } \\
\text { scaling, borders, itching, } \\
\text { koebner phenomenon, } \\
\text { polygonal and follicular } \\
\text { papules, oral mucosal } \\
\text { involvement, knee-elbow, } \\
\text { and scalp involvement, } \\
\text { family history, age, etc. }\end{array}$ & $\begin{array}{c}\mathrm{SVM}+ \\
\mathrm{KNN}+\mathrm{MLP}\end{array}$ & $\begin{array}{l}\text { System accuracy } \\
\text { is robust with a } \\
\text { faster response } \\
\text { time. }\end{array}$ & $\begin{array}{l}\text { The segmentation } \\
\text { algorithm is not } \\
\text { defined. }\end{array}$ & $97.78 \%$ \\
\hline$[22]$ & $\begin{array}{l}\text { Threshold-based } \\
\text { Adaptive Snake } \\
\text { (AS) approach }\end{array}$ & $\begin{array}{c}\text { ABCD rule + } \\
\text { Epiluminescence } \\
\text { microscopy (ELM) } \\
\text { criteria algorithm }\end{array}$ & $\begin{array}{l}\text { Features extracted in } \\
\text { ABCD rule with } \\
\text { ELM criteria. }\end{array}$ & $\begin{array}{c}\text { GA + SVM } \\
\text { with Radial } \\
\text { Basis } \\
\text { Function (RBF) }\end{array}$ & $\begin{array}{l}\text { GA lessens the } \\
\text { element } \\
\text { measurements } \\
\text { to improve } \\
\text { framework } \\
\text { execution. }\end{array}$ & $\begin{array}{l}\text { The segmentation } \\
\text { method is not } \\
\text { working properly } \\
\text { which decreases } \\
\text { system accuracy. }\end{array}$ & $88 \%$ \\
\hline [23] & - & - & - & $\begin{array}{c}\text { Multi-level } \\
\text { CNN + BVLC } \\
\text { Alexnet model }\end{array}$ & $\begin{array}{l}\text { Easy to } \\
\text { understand } \\
\text { and low } \\
\text { complexity } \\
\text { system. }\end{array}$ & $\begin{array}{l}\text { Poor efficiency of } \\
\text { the system with a } \\
\text { lower recall and } \\
\text { precision rate. } \\
\text { The segmentation } \\
\text { and feature } \\
\text { extraction method } \\
\text { is not defined. }\end{array}$ & $70 \%$ \\
\hline [29] & - & $\begin{array}{l}\text { Canny edge } \\
\text { detection }\end{array}$ & $\begin{array}{l}\text { The CED method } \\
\text { detects sharp edges } \\
\text { with image } \\
\text { boundaries. }\end{array}$ & $\mathrm{GA}+\mathrm{BPNN}$ & $\begin{array}{c}\text { Cloud } \\
\text { computing-based } \\
\text { skin disease } \\
\text { diagnosis system } \\
\text { deals with } \\
\text { enormous } \\
\text { amounts of } \\
\text { datasets. }\end{array}$ & $\begin{array}{l}\text { Efficient } \\
\text { segmentation is } \\
\text { absent and system } \\
\text { accuracy is also } \\
\text { undefined. }\end{array}$ & - \\
\hline [36] & - & $\begin{array}{c}\text { Pretrained } \\
\text { convolutional } \\
\text { neural network } \\
\text { (AlexNet) }\end{array}$ & $\begin{array}{l}\text { Max pooling criteria } \\
\text { evolve with 5-layer } \\
\text { convolutional } \\
\text { architecture. }\end{array}$ & $\begin{array}{c}\text { Deep } \\
\text { convolution } \\
\text { neural } \\
\text { network + ECOC } \\
\text { (Error-correcting } \\
\text { output codes) } \\
\text { linear SVM }\end{array}$ & $\begin{array}{l}\text { The smart master } \\
\text { system enhances } \\
\text { existing work with } \\
\text { an expansion } \\
\text { inexactness of } \\
3.21 \% \text { in the } \\
\text { confusion matrix. }\end{array}$ & $\begin{array}{l}\text { Poor system } \\
\text { performance due } \\
\text { to proper } \\
\text { segmentation } \\
\text { approach is } \\
\text { undefined. }\end{array}$ & $86.21 \%$ \\
\hline
\end{tabular}




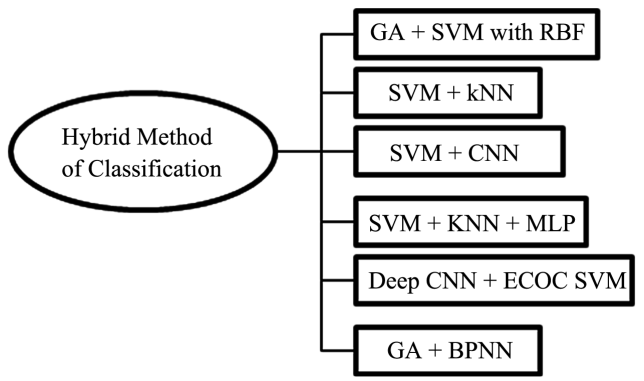

Figure 6. Several hybrid classification methods.

From the above Table 3, we can say that the method SVM with kNN is efficient than other hybrid classification methods, as this hybrid classification method ensures high accuracy. The highest accuracy of the efficient hybrid classification method of skin disease is about $98 \%$.

\section{Challenges of Hybrid Skin Disease Detection Systems}

There are many challenges in designing an automated skin disease detection system. There is an insufficiency of datasets for hybrid segmentation methods. If the system uses no efficient segmentation technique, then only a manually cropped portion of the skin lesion image does not produce good features. When the features are not properly extracted, the exact skin disease will not be properly classified by the hybrid skin disease classification system. If the test images are not preprocessed and segmented properly, the mobile-based automated skin disease detection system will be threatening. For overcoming this challenge, the input images must use a denoising technique along with a proper segmentation technique. For a good detection system, the availability of optimized segmentation, feature extraction, and classification techniques are really challenging issues.

\section{Conclusions and Future Research Directions}

Nowadays the huge population is seriously affected by various skin diseases. Therefore, the skin disease detection system plays a vital role in identifying these diseases accurately at the initial stage. In this research, we have reviewed several dominant state-of-the-art hybrid methodologies for segmentation, feature extraction, and classification for detecting skin diseases accurately. This review study concludes that the uniform distribution-based segmentation fused with an active contour approach is robust with a maximum system accuracy of about 97\%. Also, DWT with the PCA method is efficient than other methods for feature extraction with an accuracy of about $98 \%$. Besides, for classification, the SVM with kNN method is robust than other methods with an accuracy of about $98 \%$. Hybridization of various deep learning algorithms is important to use in skin disease detection to fulfill the design requirements. In addition, researchers should consider the computational complexity of the system in terms of time and space. Also, they should concentrate on developing more extensive label da- 
tasets as well as cloud and IoT-based skin disease monitoring systems.

\section{Conflicts of Interest}

The authors declare no conflicts of interest.

\section{Authors' Contributions}

M.A.M. studied and drafted the whole paper; M.S.U. initiated the concept, supervised the study, and fine-tuned the manuscript.

\section{References}

[1] Alcon, J.F., Ciuhu, C., ten Kate, W., Heinrich, A., Uzunbajakava, N., Krekels, G., Siem, D. and de Haan, G. (2009) Automatic Imaging System with Decision Support for Inspection of Pigmented Skin Lesions and Melanoma Diagnosis. IEEE Journal of Selected Topics in Signal Processing, 3, 14-25.

https://doi.org/10.1109/JSTSP.2008.2011156

[2] Marín, C., Alférez, G.H., Córdova, J. and González, V. (2015) Detection of Melanoma through Image Recognition and Artificial Neural Networks. World Congress on Medical Physics and Biomedical Engineering, Toronto, 7-12 June 2015, Vol. 51, 832-835. https://doi.org/10.1007/978-3-319-19387-8_204

[3] Suganya, R. (2016) An Automated Computer-Aided Diagnosis of Skin Lesions Detection and Classification for Dermoscopy Images. 2016 th International Conference on Recent Trends in Information Technology, Chennai, 8-9 April 2016, Vol. 1, 155-159. https://doi.org/10.1109/ICRTIT.2016.7569538

[4] Adjed, F., Faye, I., Ababsa, F., Gardezi, S.J. and Dass, S.C. (2016) Classification of Skin Cancer Images Using Local Binary Pattern and SVM Classifier. 4th International Conference on Fundamental and Applied Sciences (ICFAS), Kuala Lumpur, 1787, 1-6. https://doi.org/10.1063/1.4968145

[5] Firdaus, N.H., Azmi, M., Md Sarkan, H., Yahya, Y. and Chuprat, S. (2016) ABCD Rules Segmentation on Malignant Tumor and Benign Skin Lesion Images. $20163 \mathrm{rd}$ International Conference on Computer and Information Sciences (ICCOINS), 1, 66-70.

[6] Nezhadian, F.K. and Rashidi, S. (2017) Melanoma Skin Cancer Detection Using Color and New Texture Features. 2017 Artificial Intelligence and Signal Processing Conference (AISP), Shiraz, 25-27 October 2017, Vol. 1, 1-5.

https://doi.org/10.1109/AISP.2017.8324108

[7] Rathod, J., Waghmode, V., Sodha, A. and Bhavathankar, P. (2018) Diagnosis of Skin Diseases Using Convolutional Neural Networks. Proceedings of the 2nd International Conference on Electronics, Communication and Aerospace Technology (ICECA), Coimbatore, 29-31 March 2018, Vol. 2, 1048-1051. https://doi.org/10.1109/ICECA.2018.8474593

[8] Wei, L.S., Gan, Q. and Ji, T. (2018) Skin Disease Recognition Method Based on Image Color and Texture Features. Computational and Mathematical Methods in Medicine, 2018, Article ID: 8145713. https://doi.org/10.1155/2018/8145713

[9] Carrera, E.V. and Ron-Dominguez, D. (2018) A Computer-Aided Diagnosis System for Skin Cancer Detection. 4th International Conference on Technology Trends, In: Botto-Tobar, M., Pizarro, G., Zúñiga-Prieto, M., D’Armas, M. and Zúñiga Sánchez, M., Eds., Technology Trends. CITT 2018. Communications in Computer and Information Science, Vol. 895, Springer, Cham, 553-563. 
https://doi.org/10.1007/978-3-030-05532-5_42

[10] Arora, G., Dubey, A.K. and Jaffery, Z.A. (2018) Classifiers for the Detection of Skin Cancer. In: Satapathy, S., Bhateja, V. and Das, S., Eds., Smart Computing and Informatics. Smart Innovation, Systems and Technologies, Vol. 78, Springer, Singapore, 351-360. https://doi.org/10.1007/978-981-10-5547-8_36

[11] Lu, M., Liu, Y., He, W. and Li, X. (2019) Skin Roughness Evaluation Method Based on Gray Level Co-Occurrence Matrix. The 31 st Chinese Control and Decision Conference (2019 CCDC), 8, 5671-5674.

[12] Al Mamun, Md. and Uddin, M.S. (2020) A Comparative Study among Segmentation Techniques for Skin Disease Detection Systems. In: Kaiser, M.S., Bandyopadhyay, A., Mahmud, M. and Ray, K., Eds., Proceedings of International Conference on Trends in Computational and Cognitive Engineering-TCCE 2020, Vol. 1309, Springer, Singapore, 155-167. https://doi.org/10.1007/978-981-33-4673-4_14

[13] Jain, Y.K. and Jain, M. (2012) Comparison between Different Classification Methods with Application to Skin Cancer. International Journal of Computer Applications, 53, No. 11. https://doi.org/10.5120/8465-2386

[14] Elgamal, M. (2013) Automatic Skin Cancer Images Classification. International Journal of Advanced Computer Science and Applications, 4, 287-294.

https://doi.org/10.14569/IJACSA.2013.040342

[15] Goel, R. and Singh, S. (2015) Skin Cancer Detection using GLCM Matrix Analysis and Back Propagation Neural Network Classifier. International Journal of Computer Applications, 112, 42-47.

[16] Sumithra, R., Suhil, M. and Guru, D.S. (2015) Segmentation and Classification of Skin Lesions for Disease Diagnosis. Procedia Computer Science, 45, 76-85. https://doi.org/10.1016/j.procs.2015.03.090

[17] Premaladha, J. and Ravichandran, K.S. (2016) Novel Approaches for Diagnosing Melanoma Skin Lesions Through Supervised and Deep Learning Algorithms. Journal of Medical Systems, 40, Article No. 96. https://doi.org/10.1007/s10916-016-0460-2

[18] Almansour, E. and Jaffar, M.A. (2016) Classification of Dermoscopic Skin Cancer Images Using Color and Hybrid Texture Features. International Journal of Computer Science Network and Security, 16, 135-139.

[19] Taufiq, M.A., Hameed, N., Anjum, A. and Hameed, F. (2016) m-Skin Doctor: A Mobile-Enabled System for Early Melanoma Skin Cancer Detection Using Support Vector Machine. In: Giokas, K., Bokor, L. and Hopfgartner, F., Eds., eHealth $360^{\circ}$ : International Summit on eHealth, Springer, Cham, 468-475.

https://doi.org/10.1007/978-3-319-49655-9_57

[20] Lahijanian, B., Farahani, F.V. and Zarandi, M.H.F. (2016) New Multiple Classifier System for Diagnosis of Erythemato-Squamous Diseases Based on Rough Set Feature Selection. 2016 IEEE International Conference on Fuzzy Systems (FUZZ), Vancouver, 24-29 July 2016, Vol. 1, 2309-2316.

https://doi.org/10.1109/FUZZ-IEEE.2016.7737981

[21] Joseph, S. and Panicker, J.R. (2016) Skin Lesion Analysis System for Melanoma Detection with an Effective Hair Segmentation Method. 2016 International Conference on Information Science (ICIS), Kochi, 12-13 August 2016, Vol. 1, 91-96. https://doi.org/10.1109/INFOSCI.2016.7845307

[22] Tan, T.Y., Zhang, L. and Jiang, M. (2016) An Intelligent Decision Support System for Skin Cancer Detection from Dermoscopic Images. 2016 12th International Conference on Natural Computation, Fuzzy Systems and Knowledge Discovery 
(ICNC-FSKD), Changsha, Vol. 3, 2194-2199.

[23] Liao, H., Li, Y.C. and Luo, J.B. (2016) Skin Disease Classification versus Skin Lesion Characterization: Achieving Robust Diagnosis using Multi-label Deep Neural Networks. 23rd International Conference on Pattern Recognition (ICPR), Cancún, 4-8 December 2016, 355-360. https://doi.org/10.1109/ICPR.2016.7899659

[24] Alquran, H., Abu Qasmieh, I., Alqudah, A.M., Alhammouri, S., Alawneh, E., Abughazaleh, A. and Hasayen, F. (2017) The Melanoma Skin Cancer Detection and Classification using Support Vector Machine. 2017 IEEE Jordan Conference on Applied Electrical Engineering and Computing Technologies (AEECT), Aqaba, 11-13 October 2017, Vol. 1, 1-5. https://doi.org/10.1109/AEECT.2017.8257738

[25] Janney, B. and Roslin, E. (2017) Classification and Detection of Skin Cancer Using Hybrid Texture Features. Proceedings of ENVOCCON, 36, 71-77.

[26] Rajesh, A. (2017) Classification of Malignant Melanoma and Benign Skin Lesion by Using Back Propagation Neural Network and ABCD Rule. IEEE International Conference on Electrical, Instrumentation and Communication Engineering (ICEICE), Karur, 27-28 April 2017, Vol. 1, 361-368.

https://doi.org/10.1109/ICEICE.2017.8191916

[27] Victor, A. and Ghalib, M.R. (2017) A Hybrid Segmentation Approach for Detection and Classification of Skin Cancer. Biomedical Research, India, 28, 6947-6954.

[28] Ajith, A., Goel, V., Vazirani, P. and Roja, M.M. (2017) Digital Dermatology: Skin Disease Detection Model Using Image Processing. International Conference on Intelligent Computing and Control Systems (ICICCS), Madurai, 15-16 June 2017, Vol. 1, 168-173. https://doi.org/10.1109/ICCONS.2017.8250703

[29] Abdulbaki, A.S., Najim, S.M. and Khadim, S.A. (2017) Eczema Disease Detection and Recognition in Cloud Computing. International Journal of Applied Engineering Research, 12, 14396-14402.

[30] Nasir, M., Khan, M.A., Sharif, M., Lali, I.U., Saba, T. and Iqbal, T. (2018) An Improved Strategy for Skin Lesion Detection and Classification Using Uniform Segmentation and Feature Selection Based Approach. Microscopy Research and Technique, 81, 528-543. https://doi.org/10.1002/jemt.23009

[31] Bajaj, L., Kumar, H. and Hasija, Y. (2018) Automated System for Prediction of Skin Disease using Image Processing and Machine Learning. International Journal of Computer Applications, 180, No.19. https://doi.org/10.5120/ijca2018916428

[32] Priya H, A.G., Anitha, J. and Poonima J, J. (2018) Identification of Melanoma in Dermoscopy Images using Image Processing Algorithms. 2018 International Conference on Control, Power, Communication and Computing Technologies (ICCPCCT), Kannur, 23-24 March 2018, Vol. 1, 553-557.

https://doi.org/10.1109/ICCPCCT.2018.8574277

[33] Harangi, B., Baran, A. and Hajdu, A. (2018) Classification of Skin Lesions Using an Ensemble of Deep Neural Networks. IEEE International Conference on Multimedia and Expo (ICME), San Diego, 18-21 July 2018, Vol. 2, 2575-2578.

https://doi.org/10.1109/EMBC.2018.8512800

[34] Hameed, N., Shabut, A.M. and Hossain, M.A. (2018) A Computer-Aided Diagnosis System for Classifying Prominent Skin Lesions Using Machine Learning. 10th Computer Science and Electronic Engineering (CEEC), Colchester, 19-21 September 2018, Vol. 1, 86-91. https://doi.org/10.1109/CEEC.2018.8674183

[35] Arasi, M.A., El-Horbaty, E.-S.M., Abdel-Badeeh, M. and El-Dahshan, E.-S.A. (2018) Classification of Dermoscopy Images Using Naïve Bayesian and Decision Tree Techniques. 1st International Conference on Information and Sciences (AICIS), 
Fallujah, 20-21 November 2018, Vol. 67, 7-12.

https://doi.org/10.1109/AiCIS.2018.00015

[36] Hameed, N., Shabut, A.M. and Hossain, M.A. (2018) Multi-Class Skin Diseases Classification Using Deep Convolutional Neural Network and Support Vector Machine. 12th International Conference on Software, Knowledge, Information Management \& Applications (SKIMA), Phnom Penh, 3-5 December 2018, Vol. 1, 14-20. https://doi.org/10.1109/SKIMA.2018.8631525

[37] Ahmed, Md.H., Ema, R.R. and Islam, T. (2019) An Automated Dermatological Images Segmentation Based on a New Hybrid Intelligent ACO-GA Algorithm and Diseases Identification Using TSVM Classifier. 1st International Conference on Advances in Science, Engineering and Robotics Technology, Dhaka, 3-5 May 2019, 894-899.

[38] Khan, M.Q., Hussain, A., Ur Rehman, S., Khan, U., Maqsood, M., Mehmood, K. and Khan, M.A. (2019) Classification of Melanoma and Nevus in Digital Images for Diagnosis of Skin Cancer. IEEE Access, 7, 90132-90144.

https://doi.org/10.1109/ACCESS.2019.2926837 